\title{
Author Correction: Genomic analyses provide insights into spinach domestication and the genetic basis of agronomic traits
}

\author{
Xiaofeng Cai $\mathbb{B}$, Xuepeng Sun, Chenxi Xu, Honghe Sun (1), Xiaoli Wang, Chenhui Ge, Zhonghua Zhang, \\ Quanxi Wang (1), Zhangjun Fei(D), Chen Jiao (1) \& Quanhua Wang (1)
}

Correction to: Nature Communications https://doi.org/10.1038/s41467-021-27432-z, published online 13 December 2021.

In the original version of this Article, Taiwan was coloured differently from mainland China in the map presented in Figure 3a. The map has now been updated according to authors' request in both PDF and HTML version of the Article. Springer Nature remains neutral with regard to jurisdictional claims in published maps and institutional affiliations.

Published online: 28 January 2022

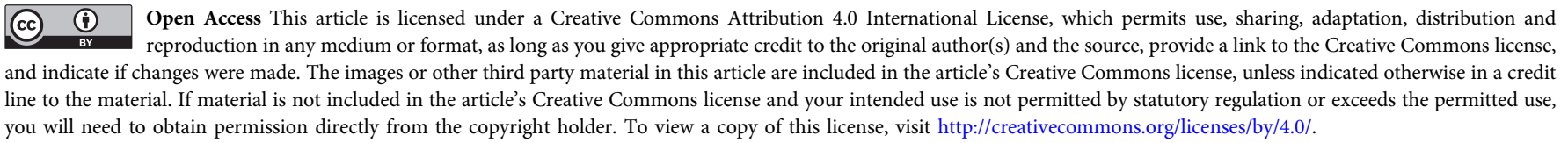
you will need to obtain permission directly from the copyright holder. To view a copy of this license, visit http://creativecommons.org/licenses/by/4.0/.

() The Author(s) 2022 